\title{
Stjepan Vukušić
}

\section{BROZOVIĆEV PROJEKT NORMIRANJA KNJIŽEVNIH NAGLASAKA}

\author{
Izvorni znanstveni rad \\ Original scientific paper \\ UDK 811.163.42-051 Brozović, D. \\ $811.163 .42^{\prime} 26^{\prime} 34$
}

Rad je prilog hrvatskoj normativnoj akcentologiji i daje kritički pregled Brozovićevih ideja u radovima koji promišljaju složenija fonološka pitanja, poput geneze, sustava i norme.

Ključne riječi: novoštokavsko naglašavanje (zapadno, istočno), konkretnost, apstrakcija, funkcioniranje

Ovaj prilog hrvatskoj normativnoj akcentologiji ne će obuhvatiti Brozovićeve radove koji se tiču naglasnih pojedinosti, nego samo one koji promišljaju složenija fonološka pitanja, poput geneze, sustava i norme.

Prvi Brozovićev rad „Akcent na dnevnome redu“1 objavljen je pred pedeset osam godina. Koje su glavne misli toga rada?

Brozović tad piše: „Čini se da je sada vrijeme da se stvari realistički postave na svoje mjesto." On dalje razvija svoju misao: kako postoje mnogi recepti, ali se ipak "oštro izdvajaju dvije krajnosti“. Na jednoj su strani „talmudisti“, zabarikadirani „iza Vuka, Maretića i Daničića i ne odustaju ni za dlaku“, a na drugoj su „glajhšalteri“, tj. oni koji su „akcenatski sistem 'pojednostavnili', a rezultat je akcenatski Babilon“. „A ako me tko pita od kojih prijeti veća opasnost našem materinskom jeziku, odgovor nije téžak: od glajhšaltera. “ Talmudisti, naime, „,nude jedan već gotov sistem (...), ali njihovi zahtjevi nisu baš privlačni“. „Glajhšalteri ne nude ništa."

U daljem tekstu autor kaže: „Do standardnog nam je jezika ostala još samo jedna ozbiljna stepenica - akcent, koji je tako važan i tako živ u našem sistemu. “

A koji je to standardni jezik za koji je akcent na dnevnome redu, kao posljednji čin standardizacije?

\footnotetext{
${ }^{1}$ Republika, 12, 1956., br. 4, str. 7.
} 
Nema dvojbe da se Brozović sa svojih dvadeset i devet godina zalaže za hrvatske pojedinosti kao što su npr. prózor : pròzor, zà mene : za mène, ali je, po njemu, klasični sistem zajedničko dobro. ${ }^{2}$

„Na hrvatsko-srpskom jezičnom području (četiri od šest naših republika) vlada golemo akcenatsko šarenilo, horizontalno (teritorijalno) i vertikalno (grad : selo, školovani : neškolovani).“ To jest nedvojbeno, ali je sigurno i to da je jezik za koji se traži rješenje upravo jezik tih četiriju republika, a nemoguće je pri takvu šarenilu naći naglasno rješenje za sve. A da je zaista nemoguće, jasno je i iz sljedećeg citata: „Rješenje ne smije narušiti postojeće jedinstvo hrvatske i srpske ortoepije, to bi bilo nepraktično, a kad bi se i pošlo tim putem, ne bi se zbog uzajamnosti živih utjecaja mogle održati dvije ortoepije u istom jeziku.“ I dalje: „Rješenje ne smije preko noći onijemiti milijune ljudi, koji u osnovi govore potomkom Vukova jezika.“ Ne, svi ne govore „potomkom Vukova jezika“, nego, barem što se tiče hrvatske strane i zapadnog dijalekta, njegovim zanemarenim i svjesno odbačenim susjedom.

Kao što se vidi: traži se rješenje za koje nema mogućnosti. A povrh toga, ni stanje jezikoslovne svijesti, ni politička volja, ni opći duh vremena nisu zreli za „Akcent na dnevnome redu“. Čak ni toliko da se učini prvi korak u pravome smjeru.

Drugi je Brozovićev rad „O normiranju književnih naglasaka“, iz 1958. Godine. ${ }^{3}$

Već u prvoj rečenici toga članka njegov autor piše da su „akcenatski standardi jedno od najbolnijih pitanja za normiranje književnog jezika (...), ali to nije samo pedagoški i praktično-ortoepski problem, nego i neophodan uvjet za cjelinu jezičnih standarda na hrvatskosrpskom jezičnom području“. ${ }^{4}$

Stanje je uglavnom isto kao i 1956., o kojem se govori u „Akcentu na dnevnome redu“. No ipak Brozoviću valja priznati pomak naprijed: „Klasični je sustav cjelina, doduše više umjetna nego se na prvi pogled čini - to će potvrditi svaki štokavski dijalektolog. "A što se tiče „plemenite Vukove stilizacije“, treba samo vidjeti kako je prošao zapadni dijalekt u Karadžićevu Srpskom rječniku iz 1818. i 1852. U prvome izdanju ni traga zapadnom dijalektu, a u drugom izdanju sveden je na ikavski izgovor staroga glasa jata. ${ }^{5}$

I u ovome se Brozovićevu članku rješava nerješivo. U njemu možemo pročitati: „Činjenica jest, da kod nas ima leksičkih dubleta, koje danas imaju uglavnom karakter hrvatski : srpski (vlak - voz, kazalište - pozorište, poduzeće - preduzeće, opći - opšti i sl.

\footnotetext{
2 Budući da dotad još nije opisan naglasni sustav u zapadnog dijalekta, klasični je sustav onaj Karadžić-Daničićev. Hrvatske su samo pojedinosti. Pri tome stavu Brozović će uglavnom ostati do kraja života.

3 Jezik, god. VI., 1957./1958., Zagreb, veljača 1958., br. 3.

${ }^{4}$ Isto, str. 65.

${ }^{5}$ V. ",Naglasak u hrvatskome književnom jeziku“, Globus 2007.
} 
- dakle sve nadgradnja), iako se radi o lingvistički istom jeziku. Ali nema niti jedne kvalitativne strukturalne razlike (možda koja sitna kvantitativna u učestalosti upotrebe ovog ili onog zajedničkog sredstva, dakle u stilističkom području), i normalno je, da je nema baš zato, što se radi o jednom jeziku. A dvojak akcenatski standard (makar jedan od njih i ne bio službeno ozakonjen) stvorio bi prvu strukturalnu razliku, umjetno je stvorio, i ne znam, kako bih dovoljno ozbiljno upozorio na takvu opasnost, koja je sasvim realna, ako se ovaj problem ne bude rješavao maksimalno pažljivo, stručno, trijezno, savjesno i promišljeno. ${ }^{.6}$

Predug je to citat, ali zauzvrat: u njemu je srž ondašnje standardizacijske i standardološke svijesti Dalibora Brozovića, kao približno tridesetogodišnjaka.

Što se sve iz tog citata dade iščitati?

- Da se u hrvatsko-srpskom slučaju radi o lingvistički istom jeziku (ne razlučivši genetski od standardnoga jezika);

- da se razlike, „koje danas imaju uglavnom karakter hrvatski : srpski“, svode na leksičke dublete stilističkoga područja;

- da "nema ni jedne kvalitativne strukturalne razlike“ u odnosu hrvatski : srpski;

- da bi "dvojak akcenatski standard“ stvorio prvu strukturalnu razliku, i to umjetno;

- da je upravo to glavna opasnost, „koja je sasvim realna“.

A na kraju zaključak: „i ne znam, kako bih dovoljno ozbiljno upozorio na takvu opasnost (...) ako se ovaj problem ne bude rješavao maksimalno pažljivo, stručno, trijezno i promišljeno".

U svezi s prvom točkom ne razlučuju se geneza i sustav tzv. dijasistema od povijesti standardnoga jezika.

Glede druge točke treba reći da dublete postoje u jednome sustavu, a ne između dvaju.

Što se tiče trećega, tj. da nema nikakve kvalitativne strukturalne razlike između hrvatskoga i srpskog književnoga jezika, valja i ovdje istaknuti da su i razlike dio strukture kao i podudarnosti. ${ }^{7}$

U četvrtoj je točki sržno strahovanje od prve strukturalne razlike koju bi stvorio „dvojak akcenatski standard“. Tu su u logičkom ratu „umjetno“ i strukturalna razlika.

Peta su i šesta točka vrhunci prethodnog citata. Tu je sveopći voluntarizam jednog vremena prešao i na standardizacijsko i normizacijsko područje književnoga jezika.

\footnotetext{
${ }^{6} \mathrm{~V}$. bilješku 5.

${ }^{7}$ V. i članak u Jeziku, god. 60, br. 5, prosinac 2013., str. 170-176.
} 
Dalje se u Brozovićevu članku govori o principu elastične stabilnosti. Ako je u hrvatskome književnom jeziku već stvorena uporabna norma na temelju zapadnog dijalekta i normizacijskih procesa iznutra, onda otpada bojazan da bi se radilo o suviše oštrom zaokretu ako bi se uporabna norma i propisala. Pod teretom jednog vremena teško je bilo ostati slobodan, čak i u znanstvenoj svijesti.

U prilog Brozoviću u ovome članku tendencijski idu znatno narasle naglasne pojedinosti koje su značajka hrvatskoga književnog jezika. Ali pritom Brozović ne dopušta da bi one bile strukturalne i sustavotvorne. One su u najvećoj mjeri sitne kvantitativne „učestalosti upotrebe ovog ili onog zajedničkog sredstva“. A sustav je izvan nas, negdje drugdje i u nečem drugome utemeljen. Hrvatski je udio u normi, pa i naglasnoj, tek u pojedinostima. To se mišljenje u tragovima znade pojaviti još i danas.

Treći je Brozovićev rad, koji obuhvaća i naglasna pitanja, njegova knjiga Standardni jezik. $^{8}$

U njoj pisac pozicije razlika između dvaju idioma u službi standardnih jezika koje nemaju strukturalna značaja, nego su - po njemu - samo supstancija, smatra zamjenjivim dubletama, dakle u jednome, istom sustavu normi, pa se prema tome radi o dvjema varijantama jednoga standardnog jezika u okviru istog dijasistema. Budući da u hrvatskosrpskom slučaju, po Brozoviću, nema strukturnih razlika, one se svode na supstanciju, tj. na dublete unutar istog sustava normi, pa su zamjenjive. Zato se u tom slučaju radi o dvjema varijantama jednoga standardnog jezika u okviru istog dijasistema. Ako pak razlike u dvama idiomima u službi standardnih jezika imaju strukturni značaj, one su nezamjenjive, pa se tu radi o dvjema normama i logično o dvama standardnim jezicima u okviru istog dijasistema ${ }^{9}$.

Međutim, pozicije razlika i pozicije podudarnosti po genezi i sustavu imaju istovjetnu strukturnu vrijednost, tj. nisu razlike supstancija, a podudarnosti struktura. Sve su pozicije struktura, pa otpada zamjenljivost/nezamjenljivost, čak i u teorijskome smislu.

Četvrti je Brozovićev tekst njegova ocjena „Uz jedno vrijedno, ali i kontroverzno akcentološko djelo - razmišljanja o genezi, sustavu i normi“. (Josip Matešić, Der Wortakzent in der serbokroatischen Schriftsprache, Heidelberg, Carl Winter Universitàtsverlag, 1970, 8 345 str.), Jezik 19, 1971-1972, br. 4-5, str. 123-139.

Već se u naslovu susrećemo s trima izrazito nosivim terminima u odnosima između sinkronije i dijakronije te onima u odnosima između genetičkih i standardnih jezika: genezom, sustavom i normom. Ali njihova poraba u ovoj ocjeni pokazuje kako nisu dostatni odgovarajući termini u svojoj općosti, nego se treba držati predmeta, pogotovo

\footnotetext{
${ }^{8}$ Teorija/usporedbe/geneza/povijest/suvremena zbilja, 1970., MH, 180.

9 Jezik, god. 60., br. 5, Zagreb, prosinac 2013., str. 170-176.
} 
kad je već i on duhovno djelovanje. U daljnjem tijeku svojeg prikaza Brozović uvodi pojam varijanata, a još ni izdaleka nije osvijetlio genezu, sustav i normu. Ono što Brozović naziva hrvatskom i srpskom varijantom svako za sebe ima svoju genezu, sustav i normu, pa baš po tome nije varijanta, a jest idiom u svojoj dijakronijskoj i standardizacijskoj prötezi. Ako su svote jednoga ili drugoga takva razvoja idiomi kao dijalektne osnovice standardnih jezika, onda su ugrađeni u te idiome i u njihovoj novoj, standardnoj službi. Ako pritom i dobro funkcioniraju, onda su svaki od njih potpun i punopravan standardni jezik, a ne tek varijanta. Odakle da se zove standardnim jezikom apstraktni idiom koji ne funkcionira jer nije konkretan, a k tomu je konkretnost per definitionem značajka standardnoga jezika ( $i$ mjesnoga govora).

Stjepan Babić u svome članku Lingvističko određenje hrvatskoga jezika ${ }^{10}$ sličnim razlozima pobija i Brozovićevu teoriju o varijantama. Babić u navedenom članku piše: „ali mi raspravu moramo proširiti jer Brozovićev zaključak da je hrvatski standardni jezik samo varijanta nije potpuno u skladu s njegovim kriterijima“. Na 135. stranici navedenog članka Stjepan Babić izvodi potpun zaključak: „Sve to jasno pokazuje da je prema Brozovićevim kriterijima jedino valjan ovakav zaključak: na jednom dijasistemu izgrađena su dva standardna jezika: hrvatski i srpski, a ne dvije varijante jednoga standardnoga jezika."

Danas je očito da su hrvatska i srpska varijanta, kojima na str. 128 svoje ocjene Matešićeve knjige Brozović započinje drugi pasus, izmozgani pojmovi pod jakim teretom ondašnjega vladajućeg mentaliteta.

Dalje Brozović u ocjeni piše: „jer radi se o sustavu, a on je apstrakcija, neovisna o konkretnostima i podrobnostima“, Dakako, i u sustavu postoje dublete i triplete, ali što onda određuje sustav? Držim da je to geneza s ukupnošću svojih inovacija. I svijest zajednice da je upravo to njezino. A to su dvije konkretne realizacije apstraktnog modela novoštokavštine koji je dijelom svačiji (polje podudarnosti), a dijelom samo jednog vlasnika (poljima individualizacije koja se sastoji od hrvatskoga i srpskoga dvojstva, a dodajmo tomu i moguće trojstvo ili pak četverstvo). Samo jedno od tog posebnoga pripadno je jednomu. A sve je ovo drugo u apstraktnom modelu, pa taj nikad ne može funkcionirati. Nema konkretnosti u tim dijelovima koji znači vlastitost, a s tim ni punine, osim da se drugima jedno nametne, a njihovo oduzme.

U nastavku će Brozović: „Sustavom se ne može govoriti, niti se može ispjevati pjesma u sustavu, niti nam se spiker javlja s ekrana sustavom. " A može se kazati da ništa od toga ne ide bez sustava, ali onoga konkretnoga koji je u nama i usklađen s normom. Sav konkretni sustav živ je u nama i vrijednosno ga osjećamo svojim. Zato u njemu i imamo sve: inventar, općerazdiobni propis, užerazdiobni propis i podudarnosti s drugima. Taj je sustav potpun i konkretan po normi. I zato funkcionira.

${ }^{10}$ Jezik, god. XVIII., br. 5, Zagreb, 1971. 
U Napomeni uz prethodni članak Uredništvo Jezika u osobi Stjepana Babića piše nakon mojeg članka Usporedbu dvaju novoštokavskih naglašavanja imenica muškog roda na $\varnothing:{ }^{11}$ „Dosad je hrvatska akcentologija vrludala između jedne teorije i druge prakse. Kamo nas je to odvelo, dobro je pokazao D. Brozović u ocjeni jedne akcentološke knjige (v. Jezik, XIX, str. 123-139). Poslije te ocjene - koja znači prekretnicu u našoj normativnoj akcentologiji, jer znatno prelazi značenje ocjene - mora se krenuti novim putem. "12

Da rezimiramo: Brozović je u ocjeni Matešićeve knjige evoluirao da sad (1972.) navodi „dvije konkretne realizacije apstraktnoga hrvatskosrpskog modela standardnoga jezika“, dok u Standardnome jeziku iz 1970. odriče tzv. hrvatskoj varijanti svaku strukturnu razliku u usporedbi sa srpskom, također varijantom. Sve su razlike pozicijā u Standardnome jeziku svedene na supstanciju, pa nemaju strukturalne vrijednosti. One su zamjenljive u okviru istog sustava normi. I tu se, dakle, spasava teorija varijanata iz Standardnog jezika. Zato dvije konkretne realizacije nemaju sustava, nisu sustavi jer je sustav jedan - negdje visoko u sferama apstrakcijā o jednome apstraktnom standardnom jeziku.

Sve je to, glede sustava negdje drugdje, a ne u nama samima. Takvo je Brozovićevo poimanje dotičnog dijela fonologija.

Tu vrijedi navesti drugačije fonološko načelo: „Glasovna strana jezika organizirana je pomoću fonoloških reprezentacija i fonoloških pravila. Fonološke reprezentacije predstavljaju mentalne strukture pohranjene u memoriji govornika nekog jezika, dok su fonološka pravila mentalne operacije koje se odvijaju u svijesti govornika prilikom oblikovanja izraza neke jezične izreke. "13 Sve je dakle u nama - i sustav i sve njegove konkretne realizacije.

Međutim, apstraktno pravilo retrakcije, tj. prenošenje naglaska nije palo na istotu idiomā. Ishodi su apstraktnoga pravila samo novoštokavske podudarnosti, a prednovoštokavske razlike tek su preznakovljene u novoštokavskome smislu. I sve je to ušlo u uporabnu normu standardnih jezika, a danas i u propisanu.

${ }^{11}$ V. Jezik 3-4, Zagreb, 1975-1976.

$12 \mathrm{U}$ toj se ocjeni Stjepan Babić vrlo galantno odnosi prema svom kolegi Daliboru Brozoviću, pripisujući mu ono što on cjelinom svog naglasnog projekta nije zaslužio: „prekretnicu u našoj normativnoj akcentologiji“. Baš on, Stjepan Babić, od samog početka do knjige Naglasak u hrvatskome književnom jeziku bio je izrazito naklonjen „prekretnici u našoj normativnoj akcentologiji“, njemu bih pridružio Milana Moguša i Božidara Finku. A s Brozovićem je za sve to vrijeme trajao zatomljeni polemos.

${ }^{13}$ Ranko Matasović, Kratka poredbenopovijesna gramatika latinskoga jezika, MH, 1997., str. 45. 
Za hrvatsku jezičnu genezu i iz nje izvedenu normu značajne su glasovne pojave u svezi s refleksom jata, oblične u svezi s gubitkom dočetnog - $\mathbf{i}$ u infinitivu, a ostale značajke, što također obilježavaju hrvatski standardni jezik, potječu iz autonomnoga razvitka samoga naglasnog sustava.

Dakle, ishodi su različitih geneza različiti sustavi i norme. Sve to izražavaju različita račvišta i različne inovacije.

Peti je Brozovićev rad „Daničićevo mjesto među istraživačima (i sudionicima) povijesti srpskoga i hrvatskog jezika (s osobitim obzirom na akcent)“. ${ }^{14}$

Brozovićeve su fascinacije dvojicom srpskih jezikoslovaca - Karadžićem i Daničićem konstante njegovih radova. Tako i ovdje kaže o Daničićevim Srpskim akcentima: „Tih šest akcenatskih rasprava predstavlja najtrajniji i najdalekosežniji Daničićev prilog normiranju standardne novoštokavštine i ostat će najsolidnijim njegovim ulogom u svoj njezinoj budućoj povijesti.“ Tim superlativima Brozović dodaje: „mogu se provesti i neke manje nadogradnje ili rekonstrukcije, ali sama zgrada ostaje bitnim svojstvom standardne novoštokavštine, naprosto zajedničkom dušom svih njezinih mogućih realizacija".

$U$ tome citatu najviše govori sintagma „neke manje nadogradnje ili rekonstrukcije“. To je, po Brozoviću, hrvatski mogući udio u naglasnoj normi zajedničkoga naglasnog sustava, a zgrada kao zajednička duša „svih mogućih realizacija“ ostaje na KaradžićDaničićevoj strani, alias na srpskoj. ${ }^{15}$

„Novoštokavština je kao idiom, kao jezična materija, dovoljno homogena da se na njezinu temelju ne mogu izgrađivati dvije (ili više) normativnih konstrukcija. "16 Tako Brozović 1981., kad se već dogodilo, barem djelomično, otkriće dvaju novoštokavskih naglašavanja (na organskoj i standardnojezičnoj razini). Od naglasnih pojedinosti na hrvatskoj strani, koje su istina u Brozovića s vremenom narastale, on je u ovom svome radu stigao do dviju konkretnih akcentuacija, od kojih je jedna „recimo zapadnonovoštokavska“. ${ }^{17}$

I dalje će Brozović: „Daničićeva zgrada nije opći dom za cjelinu standardne novoštokavštine, niti to može ikad postati (...) Treba izgraditi zapadno krilo. “18 A kad se zapadno krilo intenzivno izgrađivalo, Brozović se tomu žestoko usprotivio. Valjda u strahu od strukturnoga naglasnog dvojstva, koje jest sustavotvorno, pa narušava njegovu teoriju o dvjema varijantama jednoga standardnog jezika u okviru istog dijasistema.

\footnotetext{
${ }^{14}$ Zbornik o Đuri Daničiću, JAZU, SANU, Zagreb - Beograd, 1981., str. 63-81.

${ }^{15}$ Ne mogu se ovdje oteti prisjećanju na Brozovićev zapis na rubu teksta: „Nemojmo ići tako daleko.“ A valja ići sve dok ima puta, pa i kreti put na bespuću.

16 Isto, str. 80.

${ }^{17}$ Isto, str. 67.

18 Isto, str. 80.
} 
Uza sve neprijeporne zasluge $\mathrm{u}$ dijalektologiji, standardologiji i posebno u fonologiji hrvatskoga jezika, Brozovićev je nedostatak u tome što je apstraktni novoštokavski sustav apsolutizirao i pretvorio ga malne u mističnu esenciju (ne videći da je sustav u nama), a ono što konkretne sustave određuje smatrao tek supstancijom koja nije strukturalna ni sustavotvorna. A to mu nije jedina zamjerka. Veća je ona druga: što je svoj znatan ugled uporabio kao smetnju da se u hrvatskoj standardnoj prozodiji stvari dovedu do kraja. One se, međutim, ipak odjelotvoruju. No sjena je ovog zaslužnika pala i na Razred za filologiju HAZU. Pritom se kao izuzetne i pojedinačne mogu smatrati uloge Stjepana Babića, Milana Moguša i Božidara Finke, koji jesu bili za prekretnicu te su i na suprasegmentnome planu dali svoje žive prinose.

Budući da je jezik struktura i na svim razinama odsječnoga plana, a sve su te strukture pohranjene u našem mentalnom ustrojstvu, povezane s vrijednošću, bit će da i za njih - mutatis mutandis - vrijedi sve ono što je u ovome radu rečeno za nadodsječni plan.

\section{POPIS LITERATURE}

\section{Babić 1971}

Babić, S., „Lingvističko određenje hrvatskoga jezika", Jezik, god. XVIII., br. 5, HFD, Zagreb 1971.

Brozović 1956

Brozović, D., „Akcent na dnevnom redu“, Republika, god. 12, br. 4, Zora, Zagreb 1956.

Brozović 1957/58

Brozović, D., „O normiranju književnih naglasaka", Jezik, god. VI., br. 3, HFD, Zagreb 1957./1958.

Brozović 1970

Brozović, D., Standardni jezik, Matica hrvatska, Zagreb 1970.

Brozović 1971-1972

Brozović, D., „Uz jedno vrijedno, ali i kontroverzno akcentološko djelo razmišljanja o genezi, sustavu i normi“. (Josip Matešić, Der Wortakzent in der serbokroatischen Schriftsprache, Heidelberg, Car Winter - Universitätsverlag, 1970., 345 str.), Jezik 19, br. 4-5, 1971. 1972., str. 123-139.

\section{Brozović 1981}

Brozović, D., „Daničićevo mjesto među istraživačima (i sudionicima) povijesti srpskoga i hrvatskog jezika (s osobitim obzirom na akcent)", Zbornik o Đuri Daničiću, JAZU, SANU, Zagreb-Beograd 1981., str. 63-81+2 karte.

Matasović 1997 Matasović, R., Kratka poredbenopovijesna gramatika latinskoga jezika, MH, 1997.

Vukušić-Zoričić-Grasselli-Vukušić 2007 Vukušić, S., Zoričić, I., GrasselliVukušić, M., Naglasak u hrvatskome književnom jeziku, Globus, Zagreb 2007.

\section{Vukušić 1975-1976} Vukušić, S., „Usporedbe dvaju novoštokavskih naglašavanja imenica muškog roda na -o", Jezik 3-4, HFD, Zagreb 1975.-1976. 


\section{Vukušić 2013}

Vukušić, S., „Naglasno usavršavanje hrvatskoga jezika IV.", Jezik, god. 60., br. 5, HFD, Zagreb 2013.

\section{SAŽETAK}

Dalibor je Brozović uvijek zauzet svojom mišlju da postoji samo jedan sustav novoštokavske akcentuacije. Taj je sustav apstraktan i izvan nas. Samo pojedinosti pripadaju hrvatskomu i srpskom jeziku.

Doista, međutim, postoje do danas dva naglasna sustava: zapadni i istočni. Štoviše, ti su sustavi konkretni. Oni se sastoje od svojih novoštokavskih podudarnosti i svojih posebnosti. Uostalom, konkretnost $i$ jest značajka književnoga jezika. Zbog toga dva sustava i funkcioniraju, dok apstraktni ne funkcionira.

I sve je to u nama.

\section{RÉSUMÉ}

Le project de Dalibor Brozović de l' accentuation normative de la langue littéraire

D. Brozović était toujours preocupé par ses idées qu' existe seul et unique système d'accentuation nouveauštokavienne. Ce système est abstrait et hors de nous. Seulement particularités appartiennent à la croate et serbe.

Cependant existent, jusqu' à présent, deux systèms accentuels: cett' occidental et cett' oriental. De plus, ces systèms sont concrets. Ils sont composés de ses correspondances nouveauštokaviennes el ses singularités. En outre, le concret est caracteristique de la langue littéraire. A cause de cela deux systèms fonctionnent.

Et tout cela est chez nous.

Mots-clés: système d'accentuation nouveauštokavienne, concret, abstraction, fonctionnement 